\title{
Liposomal nanoparticles encapsulating iloprost exhibit enhanced vasodilation in pulmonary arteries
}

This article was published in the following Dove Press journal:

International Journal of Nanomedicine

7 July 2014

Number of times this article has been viewed

Pritesh P Jain'

Regina Leber ${ }^{1,2}$

Chandran Nagaraj'

Gerd Leitinger ${ }^{3}$

Bernhard Lehofer ${ }^{4}$

Horst Olschewski ${ }^{1,5}$

Andrea Olschewski ${ }^{1,6}$

Ruth Prassl ${ }^{1,4}$

Leigh M Marsh'

'Ludwig Boltzmann Institute for Lung Vascular Research, ${ }^{2}$ Biophysics

Division, Institute of Molecular

Biosciences, University of Graz,

${ }^{3}$ Research Unit Electron Microscopic

Techniques, Institute of Cell

Biology, Histology, and Embryology,

${ }^{4}$ Institute of Biophysics, ${ }^{5}$ Division

of Pulmonology, Department of

Internal Medicine, ${ }^{6}$ Department of

Anesthesiology and Intensive Care

Medicine, Medical University of Graz,

Graz, Austria
Correspondence: Leigh M Marsh Ludwig Boltzmann Institute for Lung Vascular Research, Stifitingtalstrasse 24, Graz 8010, Austria

Tel +433163857 29II

Fax +43 31638572058

Email leigh.marsh@lvr.lbg.ac.at

\begin{abstract}
Prostacyclin analogues are standard therapeutic options for vasoconstrictive diseases, including pulmonary hypertension and Raynaud's phenomenon. Although effective, these treatment strategies are expensive and have several side effects. To improve drug efficiency, we tested liposomal nanoparticles as carrier systems. In this study, we synthesized liposomal nanoparticles tailored for the prostacyclin analogue iloprost and evaluated their pharmacologic efficacy on mouse intrapulmonary arteries, using a wire myograph. The use of cationic lipids, stearylamine, or 1,2-di-(9Z-octadecenoyl)-3-trimethylammonium-propane (DOTAP) in liposomes promoted iloprost encapsulation to at least $50 \%$. The addition of cholesterol modestly reduced iloprost encapsulation. The liposomal nanoparticle formulations were tested for toxicity and pharmacologic efficacy in vivo and ex vivo, respectively. The liposomes did not affect the viability of human pulmonary artery smooth muscle cells. Compared with an equivalent concentration of free iloprost, four out of the six polymer-coated liposomal formulations exhibited significantly enhanced vasodilation of mouse pulmonary arteries. Iloprost that was encapsulated in liposomes containing the polymer polyethylene glycol exhibited concentration-dependent relaxation of arteries. Strikingly, half the concentration of iloprost in liposomes elicited similar pharmacologic efficacy as nonencapsulated iloprost. Cationic liposomes can encapsulate iloprost with high efficacy and can serve as potential iloprost carriers to improve its therapeutic efficacy.
\end{abstract}

Keywords: prostacyclin, cationic liposomes, pulmonary hypertension, wire myograph

\section{Introduction}

Prostacyclin and its analogues are potent vasorelaxing agents that have been extensively used in the treatment of several diseases, such as pulmonary hypertension (PH), peripheral vascular disease, and Raynaud's phenomenon. ${ }^{1-4}$ The first synthetic prostacyclin used in the treatment of $\mathrm{PH}$ was intravenous epoprostenol., 5 Since then, more stable prostacyclin analogues, such as iloprost and treprostinil, have become a mainstay in PH treatment. ${ }^{1,7,8}$ However, side effects are also apparent, which include flushing, cough, and flu-like symptoms. To improve the pharmacological profile of the drug, we investigated the use of liposomal nanoparticles as carrier systems.

Over the last few years, liposomal nanoparticles have gained increased interest as drug delivery systems. Liposomal drug encapsulation can minimize drug-related side effects, reduce local irritation, and also increase therapeutic effects via sustained release. ${ }^{9,10}$ Modification of the liposome's surface chemistry by the addition of polymers can improve stability. ${ }^{11,12}$ To date, several liposomal drugs have been approved for clinical use, including encapsulated doxorubicin and amphotericin B, for the treatment of cancer and fungal infections, respectively. ${ }^{13-15}$ Approved intravenous liposomal formulations for doxorubicin contain neutral lipids or lipids conjugated to the polymer 
polyethylene glycol (PEG), and cholesterol. ${ }^{14,16}$ In contrast, liposomal vincristine contains sphingomyelin and cholesterol as main lipid components. ${ }^{17,18}$ The liposomal vincristine formulation, Marqibo ${ }^{\circledR}$ (Talon Therapeutics, Inc, San Mateo, CA, USA), was approved for the therapy of leukemia only recently. ${ }^{17,18}$ In addition to intravenous application, other drug administration routes, including inhalation therapy have become the focus of interest for liposomal delivery systems. For inhalation purpose, neutral lipids, like phosphatidylcholines, and anionic lipids, like phosphatidylglycerols, were used for encapsulation of beclomethasone, ${ }^{19,20}$ fasudil,${ }^{21}$ and vasoactive intestinal peptide (VIP), ${ }^{22}$ respectively. None of these formulations has yet attained clinical status; however, many more liposomal formulations are in the pipeline. ${ }^{13}$

Previously, Kleemann et al described liposomal encapsulation of the vasodilator iloprost, using conventional liposomes composed of phosphatidylcholine and cholesterol, and also sterically stabilized liposomes, using PEG. ${ }^{23}$ However, their study was limited by low encapsulation efficiencies. Here, we investigated the feasibility of tailoring liposomal formulations to improve the encapsulation efficiency of iloprost and enhance its pharmacologic efficacy. Since iloprost chemically possesses negative charge at $\mathrm{pH}$ 7.4, we examined the possibility of using cationic lipids to promote encapsulation. We developed and characterized several novel liposomal formulations that were optimized for the delivery of iloprost, and we tested their effects on cell viability and their pharmacologic efficacy on mouse intrapulmonary arteries, using a wire myograph.

\section{Materials and methods Materials}

Lipids, dipalmitoylphosphatidylcholine (DPPC), 1-palmitoyl-2oleoyl-sn-glycero-3-phosphocholine (POPC), cholesterol, [methoxy (polyethyleneglycol)-2000]-dipalmitoyl-phosphatidylethanolamine (DPPE-PEG ${ }_{2000}$ ), and 1,2-di(9Z-octadecenoyl)-3-trimethylammonium-propane (DOTAP), were purchased from Avanti Polar Lipids (Alabaster, AL, USA). Stearylamine (SA) was purchased from Sigma-Aldrich Corp (St Louis, MO, USA). Polyvinylpyrrolidone (PVP) was a kind gift from BASF (Ludwigshafen, Germany). U-46619 was purchased from Enzo Life sciences (Farmingdale, NY, USA) and dissolved in 99\% dimethylsulfoxide (DMSO). Anhydrous iloprost was a generous gift from Bayer AG (Leverkusen, Germany). Iloprost was prepared as a stock solution of $500 \mu \mathrm{g} / \mathrm{mL}$ in chloroform:methanol (C/M) $2: 1$, volume/volume $(\mathrm{v} / \mathrm{v})$.

\section{Methods}

\section{Preparation of liposomes}

Liposomes were prepared by the thin film rehydration method. ${ }^{24}$ Briefly, anhydrous iloprost (50 $\mu \mathrm{g}$ ), lipids ( $6 \mathrm{mg}$ ), and, if appropriate, PVP were dissolved in $\mathrm{C} / \mathrm{M}$ and mixed. Organic solvents were then evaporated under inert nitrogen to form a lipid film. The lipid film was rehydrated with $1 \mathrm{~mL} 10 \mathrm{mM}$ Tris/ $\mathrm{HCl}, 154 \mathrm{mM}$ sodium chloride $\mathrm{pH} 7$ at room temperature (RT), with repeated vortexing, for 1 hour, and this was followed by six freeze and thaw cycles. Liposomes were then extruded through Whatman $200 \mathrm{~nm}$ polycarbonate filters (Avanti Polar Lipids) using an Avanti ${ }^{\circledR}$ Mini-Extruder (Avanti Polar Lipids).

\section{Separation of nonencapsulated iloprost from liposomes}

Nonencapsulated iloprost was separated from liposomes by centrifugation, for 10 minutes at $4,000 \times g$, using an Amicon $^{\circledR}$ Ultra-4 centrifugal filter unit with Ultracel 100 membrane UFC810096 (Merck KGaA, Darmstadt Germany). Iloprostloaded liposomes were retained in the upper compartment. Nonencapsulated iloprost was absorbed by the cellulose membrane of the filter device and was eluted with $70 \%$ ethanol. The filter was washed twice with rehydration buffer, and then the liposomes were overlaid with argon and stored at $4^{\circ} \mathrm{C}$ until further analysis.

\section{Determination of encapsulation efficiency of iloprost in liposomes}

We developed a simple and rapid chromatographic method to estimate iloprost encapsulation in the liposomes. The amount of iloprost in the liposomes was determined by semiquantitative thin-layer chromatography (TLC). Iloprost-loaded liposomes were first subjected to phospholipid Folch extraction. ${ }^{25}$

Briefly, the lipids were extracted in C/M 2:1 (v/v) using 20 times the liposome. For phase separation, 0.2 volumes of $0.034 \%$ magnesium chloride were added. The mixture was centrifuged at $1125 \times g$ for 5 minutes at RT. The lower organic phase, containing lipids and iloprost, was subjected to evaporation under inert nitrogen, to obtain dried lipid extracts. The lipids were resolved in small quantities of $\mathrm{C} / \mathrm{M}(2: 1 \mathrm{v} / \mathrm{v})$ and applied to a precoated silica TLC plate (TLC Silica Gel 60; Merck KGaA). The mobile phase consisted of chloroform:methanol:ammonia $(65: 35: 1.5, \mathrm{v} / \mathrm{v} / \mathrm{v})$. For visualization of the lipid bands, the dry plate was dipped in 20\% copper sulfate solution containing 9\% phosphoric acid, and heated at $190^{\circ} \mathrm{C}$. Iloprost was applied as a reference. Liquid chromatography tandem mass spectroscopy (LC-MS/MS) (4000 QTRAP ${ }^{\circledR}$, AB SCIEX, Framingham, MA, USA) was used for accurate quantification of iloprost (range of detection $5 \mathrm{ng}-5 \mu \mathrm{g}$ ). 


\section{Liposome particle size}

Average particle size and polydispersity index (PDI) were measured by photon correlation spectroscopy, using a Zetasizer 3000HS (Malvern Instruments, Malvern, UK). Empty and iloprost-loaded liposomes were measured after dilution to a lipid concentration of $0.03 \mathrm{mg} / \mathrm{mL}$ with ultrapure water. Particle size was analyzed by calculating the auto correlation function of the detected intensity. The PDI value of liposome preparations was obtained from the width of the size distribution.

\section{Liposome zeta $(\zeta)$ potential}

The $\zeta$-potential was determined by laser doppler electrophoresis using a Zetasizer Nano ZS ZEN3600 (Malvern Instruments). All measurements were performed at RT, using samples diluted to a lipid concentration of $0.3 \mathrm{mg} / \mathrm{mL}$ with Tris/HCl buffer (10 mM Tris/Cl, $\mathrm{pH} 7.0,2 \mathrm{mM} \mathrm{CsCl})$, and were carried out in triplicates of at least ten runs.

\section{Negative staining transmission electron microscopy} Next, $4.5 \mu \mathrm{L}$ of pure (empty) and iloprost-loaded liposomes $(0.6 \mathrm{mg} / \mathrm{mL})$ were placed on carbon-coated copper grids. After a 1-minute incubation, the excess sample was blotted off and replaced by the staining reagent ( $1 \%$ aqueous uranyl acetate). This treatment was repeated twice, each with 30 seconds incubation times. Samples were visualized using an FEI Tecnai ${ }^{\circledR} \mathrm{G}^{2} 20$ Transmission Electron Microscope (FEI Co, Hillsboro, OR, USA) at $120 \mathrm{kV}$ as acceleration voltage, with the help of a Gatan Ultrascan ${ }^{\circledR}$ 1000 CCD camera (Gatan, Inc., Pleasanton, CA, USA) at $2 \mathrm{k} \times 2 \mathrm{k}$ resolution.

\section{Freeze-fracture transmission electron microscopy}

Pure and iloprost-loaded liposomes $(6 \mathrm{mg} / \mathrm{mL})$ were mixed with $30 \%$ glycerol and were frozen in liquid propane. Samples were fractured in a Balzers BAF 400D freezefracture apparatus (Oerlikon Balzers Coating AG, Balzers, Liechtenstein) at pressures around $1.3 \times 10^{-5} \mathrm{~Pa}$, and replicas were made. The replicas were cleaned by introducing them into a $12 \%$ sodium hypochlorite solution for approximately 3 hours, with further overnight storage in $50 \% \mathrm{NaOH}$. The replicas were then washed three times with double-distilled water before loading them on uncoated copper grids. The samples were visualized as previously described in the last section.

\section{Cell viability}

Human pulmonary artery smooth muscle cells (hPASMCs) were isolated from pulmonary arteries from nontransplanted donor lungs, as previously described elsewhere. ${ }^{26}$ A549 cells were purchased from Cell Lines Service, Eppelheim, Germany. The effect of liposomes on cell viability was evaluated using an MTS assay, according to the manufacturer's instructions (CellTiter $96^{\circledR}$ Aqueous One Solution Cell Proliferation Assay; Promega Corp, Fitchburg, WI, USA). A549 cells were cultured in Gibco ${ }^{\circledR}$ Dulbecco's Modified Eagle's Medium Nutrient Mixture F-12 (DMEM/ F12) medium (Life Technologies Corp, Carlsbad, CA, USA) containing glutamine and 10\% fetal calf serum (A549), and hPASMC were cultured in VascuLife ${ }^{\circledR}$ SMC medium (Lifeline Cell Technology, Carlsbad, CA, USA) and seeded on 96-well plates, at a density of $4 \times 10^{4}$ cells (hPASMC) and $2 \times 10^{4}$ cells (A549), respectively, per well. The cells were incubated with either $0.2 \mu \mathrm{M}$ or $1 \mu \mathrm{M}$ of free or liposomal iloprost, respectively, for 24 hours. Control liposomes (with lipid concentration of $6 \mathrm{mg} / \mathrm{mL}$ ) were added at the same dilution factor as their respective liposomes. Sodium dodecyl sulfate, at $0.1 \%$ and $0.5 \%$ weight/volume, was used as a positive control for the hPASMC and A549 cells, respectively. Postincubation, MTS/phenazine methosulfate was added with further incubation for 2 hours. Absorbance of the produced formazan was recorded at $490 \mathrm{~nm}$, using a 96-well plate reader (GloMax ${ }^{\circledR}$-Multi Detection System; Promega Corp).

\section{Isolation of tertiary pulmonary arteries}

BALB/c mice (male or female), 20-25 weeks old, were used in the study. The mice were preanesthetized with isoflurane and euthanized with an intraperitoneal injection of ketamine $(500 \mathrm{mg} / \mathrm{kg}$ ) and xylazine $(70 \mathrm{mg} / \mathrm{kg}$ ), according to the European guidelines 2010/63/EU. The heart and lungs were removed and the tertiary intrapulmonary arteries isolated with help of a stereo zoom microscope SZX7 (Olympus Corp, Tokyo, Japan) (Figure S1). The arteries were cleaned of surrounding adipose and connective tissue and cut into segments $3-4 \mathrm{~mm}$ in length, for use in isometric tension measurements (myograph studies). All tissues were preserved in an ice-cold physiologic salt solution of $140.5 \mathrm{mM} \mathrm{NaCl}, 5.5 \mathrm{mM} \mathrm{KCl}, 1.5 \mathrm{mM}$ $\mathrm{CaCl}_{2}, 1 \mathrm{mM} \mathrm{MgCl}, 10 \mathrm{mM}$ glucose, $0.5 \mathrm{mM} \mathrm{Na}_{2} \mathrm{HPO}_{4}$, $0.5 \mathrm{mM} \mathrm{KH}_{2} \mathrm{PO}_{4}$, and $10 \mathrm{mM}$ HEPES (4-(2-hydroxyethyl)1-piperazineethanesulfonic acid) solution $\mathrm{pH} 7.4$, throughout the dissection procedure.

\section{Isometric tension measurements in pulmonary arteries}

The pulmonary arteries were positioned between jaws with the help of tungsten wires, in myograph chambers (Multi Wire Myograph System-620M; Danish MyoTechnology A/S, 
Aarhus, Denmark) containing physiologic salt solution and continuously aerated with $21 \% \mathrm{O}_{2}, 5 \% \mathrm{CO}_{2}$, and balanced $\mathrm{N}_{2}$, at $37^{\circ} \mathrm{C}$. The myograph chambers were connected to force transducers for isometric measurements (PowerLab ${ }^{\circledR} 8 / 35$; ADInstruments, Dunedin, New Zealand). The pulmonary arteries were incubated at $37^{\circ} \mathrm{C}$, and a basal tension of $2 \mathrm{mN}$ was applied. The arteries were allowed to stabilize for 45 minutes. Physiologic salt solution containing $120 \mathrm{mM} \mathrm{KCl}$ was used to determine viability and adequate contractility of the tissues. The arteries were stimulated three times, using $120 \mathrm{mM} \mathrm{KCl}$ to obtain reproducible contractions. Arteries that did not respond to these repeated stimuli were not included in the study.

\section{Preparation of iloprost for wire myograph}

Iloprost dissolved in $\mathrm{C} / \mathrm{M}$ was dried by evaporation and dissolved in 96\% ethanol, and diluted 1:1000 with physiologic salt solution. The final concentration of ethanol was $0.096 \mathrm{vol} \%$.

\section{lloprost-induced relaxation of preconstricted pulmonary arteries}

Initially, a concentration-response curve for mouse pulmonary arteries was established by adding cumulative doses of the thromboxane analogue, U-46619 (0.001-3 $\mu \mathrm{M})$. For subsequent experiments, the arteries were contracted with the half-maximal effective concentration $\left(\mathrm{EC}_{50}\right), 0.03 \mu \mathrm{M}$, of U-46619. Following stable contraction ( $\sim 30$ minutes postaddition of U-46619), the arteries were challenged with one concentration of free iloprost $(1 \mu \mathrm{M}, 3 \mu \mathrm{M}, 10 \mu \mathrm{M}$, and $30 \mu \mathrm{M}$ ), liposomal iloprost, or control (empty) liposomal formulations, as indicated. The control liposomes were added to give the same final lipid concentration as their corresponding encapsulated formulation. In a subset of experiments, sodium nitroprusside $(10 \mu \mathrm{M})$ was added 60 minutes post-iloprost addition to confirm vessel relaxation viability.

\section{RNA isolation and real-time polymerase chain reaction (PCR) measurements}

Total RNA was isolated, using the RNeasy Mini kit (Peqlab, Erlangen, Germany), from the mouse pulmonary arterial sections. Total RNA was reverse transcribed using the iScript ${ }^{\mathrm{TM}}$ cDNA Synthesis kit for RT-qPCR (Bio-Rad Laboratories, Hercules, CA, USA), according to manufacturer's instructions. Real-time PCR was performed using a LightCycler ${ }^{\circledR} 480$ System (F. Hoffman-La Roche, Basel, Switzerland). The PCR reactions were set up using a QuantiFast ${ }^{\circledR}$ SYBR $^{\circledR}$ Green PCR kit (Qiagen, Venlo, the Netherlands). The cycling conditions were as follows:
5 minutes at $95^{\circ} \mathrm{C},\left(5\right.$ seconds at $95^{\circ} \mathrm{C}, 5$ seconds at $60^{\circ} \mathrm{C}$, and 10 seconds at $\left.72^{\circ} \mathrm{C}\right) \times 45$. Due to the nonselective doublestrand DNA binding of the SYBR ${ }^{\circledR}$ Green I dye, melting curve analysis and gel electrophoresis were performed to confirm the specific amplification of the expected PCR product. $P B G D$ and $B 2 M$ were used as the reference genes. The difference in threshold cycle $(\mathrm{Ct})$ values for each target gene were calculated as

$$
\Delta \mathrm{Ct}=\mathrm{Ct} \text { reference gene }-\mathrm{Ct} \text { target gene. }
$$

The primer sequences were as follows $\left(5^{\prime}-3^{\prime}\right)$ EP1 GAA CCT CAG TCC TTG GCG GG, CAC CCC ATG CAT GTC TGC TC; EP2, ATA CTT AGG CCA CCG GTC CT, GGC ACT GGA CTG GGT AGA AC; EP3, ATT GCA GTT CGC CTG GCT TC, TTC AGG TTG TTC ATC ATC TGG C; EP4, CAC ACC GGG CTC CTA ACC C, GTT GAC TCC GGG GAT GGA CA; IP, CTA TCT TGG GGA ACT GCG CT, AAG CAT GCC TGT GAA GTC CT; TP, GAC TGC GAG GTG GAG ATG ATG, AGG TGG TGT CTG CAA CAA AGT; PBGD, GGT ACA AGG CTT TCA GCA TCG C; ATG TCC GGT AAC GGC GGC; B2M. CGG CCT GTA TGC TAT CCA GAA AAC C, TGT GAG GCG GGT GGA ACT GTG. The amplicons for all prostacyclin receptors were between 107-111 bp.

\section{Data analysis}

Results were expressed as mean \pm standard error of the mean (SEM), and $\mathrm{n}$ indicated the number of arteries. The concentration curve for U-46619 was expressed as percentages of contraction relative to $120 \mathrm{mM} \mathrm{KCl}$. Relaxation values were expressed as the percentage change from the U-46619-induced contraction. To obtain relaxation values for the encapsulated formulations, the relaxation values of empty liposomes were subtracted from the respective liposomal iloprost formulation. Multigroup comparisons were performed with a one-way analysis of variance (ANOVA), with either Tukey's or Dunnett's (for comparisons to a control group) post hoc test, as appropriate. Comparison between two groups was performed with a Student's $t$-test. GraphPad Prism 5 (GraphPad Software, Inc, La Jolla, CA, USA) was used. Values of $P<0.05$ were considered statistically significant.

\section{Results \\ Encapsulation efficiency of iloprost in liposomal nanoparticles}

We first developed a semiquantitative method for the rapid and easy determination of iloprost concentration using TLC 

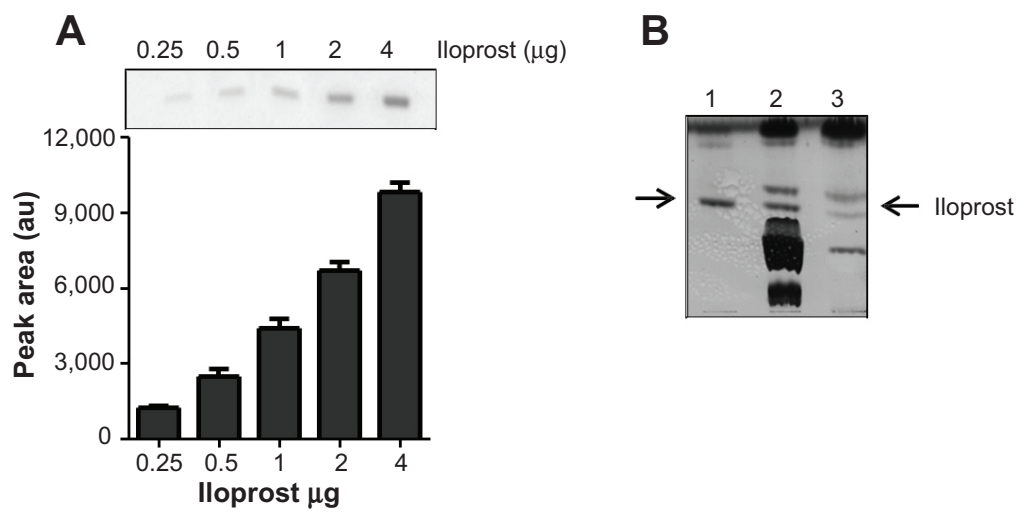

C

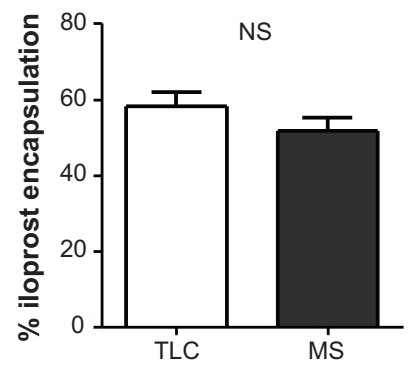

Figure I Representative TLC for detection of iloprost. (A) Detection limit for iloprost on TLC, after derivatization with copper sulfate, followed by quantification of the area occupied by the band. (B) Evaluation of iloprost $(2 \mu \mathrm{g})$ encapsulation into liposomes by TLC; nonencapsulated iloprost was removed via absorption by a cellulose membrane. Lane I= iloprost reference $(2 \mu \mathrm{g})$; lane $2=$ encapsulated iloprost; and lane $3=$ nonencapsulated iloprost eluted from the cellulose membrane. Iloprost bands on TLC are indicated by arrows. (C) Comparison of encapsulation of iloprost in liposomes via semiquantitative TLC and MS.

Abbreviations: MS, mass spectroscopy; NS, not significant; TLC, thin-layer chromatography.

(Figure 1A). Nonencapsulated iloprost was removed from liposomal formulations via adherence to cellulose membranes (Figure 1B). Comparison of the encapsulation efficiency derived by TLC to that determined by mass spectroscopy revealed similar encapsulation rates (Figure 1C).

Initially, we prepared conventional liposomes composed of DPPC and cholesterol. Hydration of the lipid film with $10 \mu \mathrm{g} / \mathrm{mL}$ aqueous iloprost (Ventavis ${ }^{\circledR}$; Bayer AG) resulted in a very low encapsulation efficiency of $\sim 4 \%$ (data not shown). In order to improve encapsulation, we incorporated anhydrous iloprost into the lipid film during liposome preparation process. We used $10 \mathrm{~mol} \% \mathrm{SA}$ as the lipid component; the polymers $\mathrm{PEG}_{2000}$ and PVP (liposomal formulations LI-1 and LI-2, respectively) were also included to impart stability. These modifications resulted in an encapsulation efficiency $\geq 60 \%$. The inclusion of cholesterol in the lipid bilayer reduced the encapsulation to $\sim 48 \%$ (LI-3) and $\sim 53 \%$
(LI-5). Replacement of SA with the cationic lipid DOTAP (LI-4 and LI-6) did not further improve encapsulation efficiency (Table 1).

The six individual formulations were then characterized for particle size, PDI, and $\zeta$-potential. Table 1 depicts the characteristics of the pure and iloprost-loaded liposomes. All liposomal formulations were $168-178 \mathrm{~nm}$ postextrusion; the incorporation of iloprost did not affect liposome size. Following separation of the encapsulated and nonencapsulated drug, no changes in size or aggregation were observed (data not shown). All formulations exhibited a PDI between 0.05 and 0.15 , suggesting a homogeneous size distribution. Characterization of the liposomes' surface charge ( $\zeta$-potential) revealed that liposomes containing the polymer PVP showed the highest $\zeta$-potential $(35-40 \mathrm{mV})$, while liposomes containing the polymer PEG possessed lower $\zeta$-potential $(8-12 \mathrm{mV})$. The morphology of one

Table I Characterization of pure (control) liposomal formulations (- iloprost) and iloprost-loaded liposomes (+ iloprost)

\begin{tabular}{|c|c|c|c|c|c|c|}
\hline $\begin{array}{l}\text { Liposome } \\
\text { formulation }\end{array}$ & Composition (molar ratios) & Iloprost & $\begin{array}{l}\text { Encapsulation } \\
\text { efficiency (\%) }\end{array}$ & $\begin{array}{l}\text { Size } \\
(\mathrm{nm})\end{array}$ & $\begin{array}{l}\text { Polydispersity } \\
\text { index }\end{array}$ & $\begin{array}{l}\text { Zeta potential } \\
(\mathrm{mV})\end{array}$ \\
\hline \multirow[t]{2}{*}{ LI-I } & POPC:SA:DPPE-PEG $2000(87: 10: 3)$ & - & - & $168.9 \pm 6.1$ & $0.12 \pm 0.02$ & $10.9 \pm 0.2$ \\
\hline & & + & $64.7 \pm 4.4$ & $168 \pm 1.6$ & $0.1 \pm 0.0$ & $12.8 \pm 0.2$ \\
\hline \multirow[t]{2}{*}{ LI-2 } & POPC:SA:PVP (87:10:3) & - & - & $171.7 \pm 3.3$ & $0.11 \pm 0.01$ & $35.6 \pm 0.2$ \\
\hline & & + & $59.6 \pm 3.3$ & $169 \pm 3.6$ & $0.1 \pm 0.0$ & $36.2 \pm 0.4$ \\
\hline \multirow[t]{2}{*}{ LI-3 } & POPC:SA:DPPE-PEG ${ }_{2000}$ :cholesterol & - & - & $174 \pm 6.9$ & $0.07 \pm 0.0$ & $1 \mathrm{I} .4 \pm 0.3$ \\
\hline & $(75.6: 8.7: 2.5: 13)$ & + & $47.7 \pm 4.3$ & $173.2 \pm 4.1$ & $0.08 \pm 0.01$ & $8.8 \pm 0.1$ \\
\hline \multirow[t]{2}{*}{ LI-4 } & POPC:DOTAP:DPPE-PEG ${ }_{2000}$ & - & - & $167.7 \pm 4$ & $0.12 \pm 0.02$ & $8.3 \pm 0.7$ \\
\hline & $(87: 10: 3)$ & + & $66.2 \pm 6.4$ & $167.8 \pm 2.7$ & $0.1 \pm 0.01$ & $9.6 \pm 0.0$ \\
\hline \multirow[t]{2}{*}{ LI-5 } & POPC:SA:PVP:cholesterol & - & - & $176.9 \pm 3.6$ & $0.05 \pm 0.0$ & $33.9 \pm 0.8$ \\
\hline & $(73.2: 8.5: 2.5: 15.6)$ & + & $53.2 \pm 7.7$ & $178.3 \pm 4.4$ & $0.09 \pm 0.01$ & $38.6 \pm 0.2$ \\
\hline \multirow[t]{2}{*}{ LI-6 } & POPC:DOTAP:PVP (87:10:3) & - & - & $173.8 \pm 8$ & $0.05 \pm 0.01$ & $37.1 \pm 1$ \\
\hline & & + & $60.6 \pm 5.7$ & $175 \pm 7.5$ & $0.09 \pm 0.01$ & $33.5 \pm 1.3$ \\
\hline
\end{tabular}

Note: Data represent mean \pm SEM.

Abbreviations: DOTAP, I,2-di-(9Z-octadecenoyl)-3-trimethylammonium-propane; DPPE-PEG ${ }_{2000}$, [methoxy (polyethyleneglycol)-2000]-dipalmitoyl-phosphatidylethanolamine; POPC, I-palmitoyl-2oleoyl-sn-glycero-3-phosphocholine; PVP, polyvinylpyrrolidone; SA, stearylamine; SEM, standard error of the mean. 
A
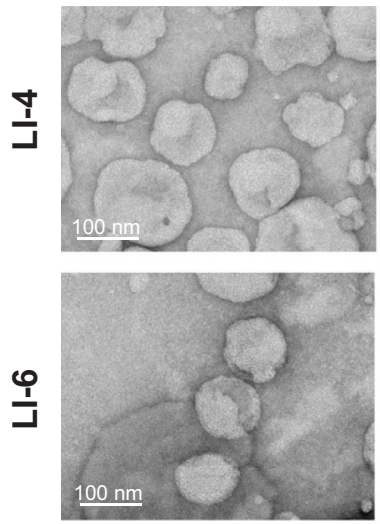
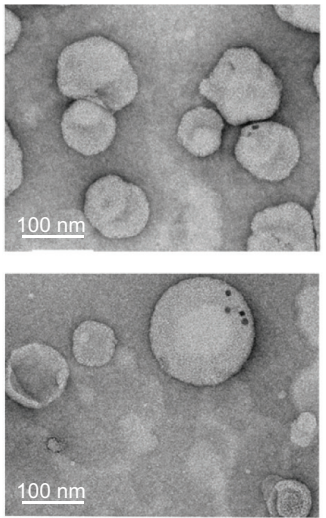

B
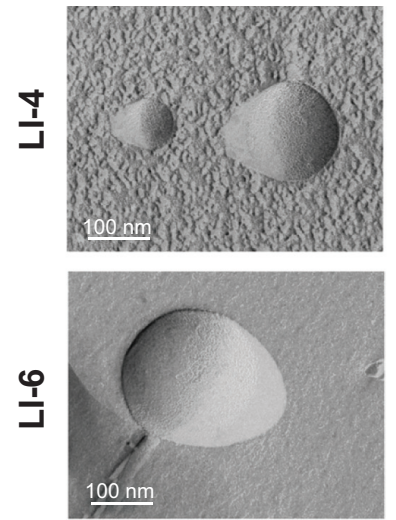
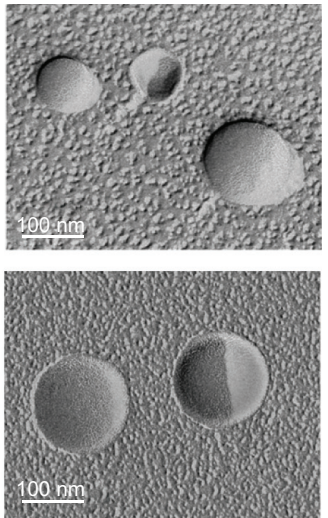

Figure 2 Transmission electron micrographs of two liposomal formulations, LI-4 and LI-6, using negative staining (A) and freeze fracture (B) of iloprost-loaded liposomes (left panels) and pure (empty) liposomes (right panels).

Note: Magnification is $\times 19,000$.

PEG (LI-6)- and one PVP (LI-4)-containing liposome, respectively, was then studied using transmission electron microscopy. Negative staining revealed that the liposomes possessed almost spherical particles Figure 2A. The average size of the liposomal nanoparticles was found to be between 100 and $200 \mathrm{~nm}$. The freeze-fracture image clearly depicted that all liposomes exhibited a spherical shape without showing any tendency for aggregation (Figure 2B). After 2 months of storage at $4^{\circ} \mathrm{C}$, iloprost encapsulation was similar to that observed of freshly prepared liposomes (Figure S2). Taken together, six different liposomal formulations that encapsulated large amounts of iloprost, at a drug to lipid molar ratio of 0.01 , were successfully developed.

A

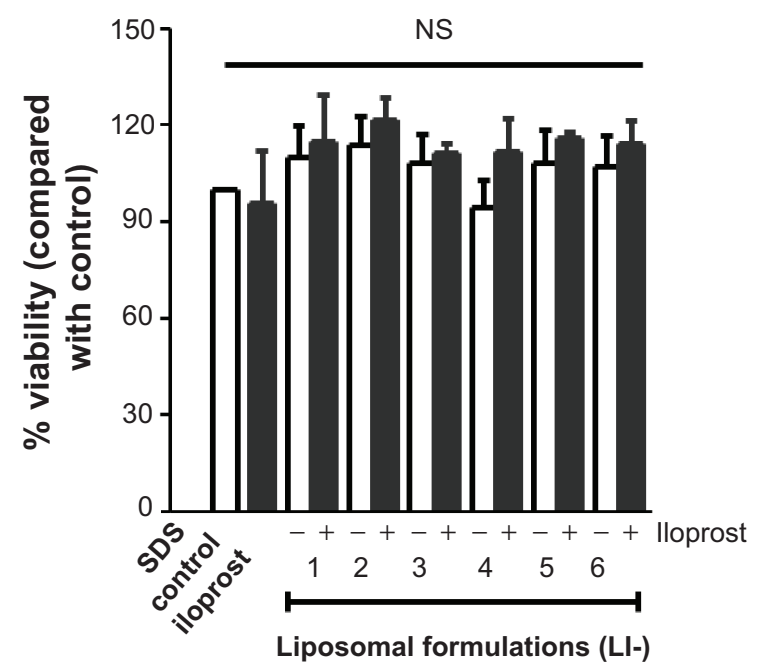

\section{Cell viability}

The effect of the liposomal formulation on cell viability was determined by an MTS assay. Primary hPASMCs and the human alveolar epithelial cell line, A549, were treated with liposomal iloprost ( $0.2 \mu \mathrm{M}$ or $1 \mu \mathrm{M}$ iloprost concentration). None of the formulations exhibited any adverse effects on hPASMC (Figure 3) or A549 cell (data not shown) viability after 24 hours of incubation.

\section{Effect of iloprost on vasorelaxation of mouse pulmonary arteries}

Pharmacological testing of encapsulated iloprost and free iloprost was determined by measuring changes in the

B

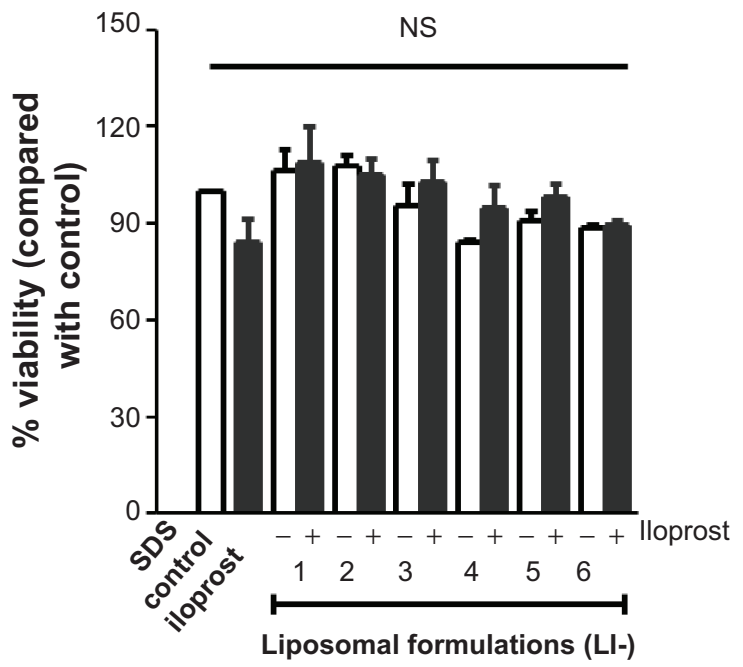

Figure 3 Viability studies of liposomes containing (A) $0.2 \mu \mathrm{M}$ or (B) I $\mu \mathrm{M}$ iloprost, on the viability of human pulmonary artery smooth muscle cells for 24 hours, $\mathrm{n}=3$. Notes: Data represent mean \pm SEM. One-way ANOVA, followed by Dunnett's multiple comparison test, was performed to calculate statistical significance. Abbreviations: ANOVA, analysis of variance; NS, not significant; SDS, sodium dodecyl sulfate; SEM, standard error of the mean. 
vascular tone of mouse intrapulmonary arteries, using a wire myograph. Cumulative concentrations of the thromboxane analogue, U-46619 $(0.01-3 \mu \mathrm{M})$, produced a concentration-dependent contraction (Figure 4A). The $\mathrm{EC}_{50}$ of U-46619 was determined to be $0.03 \mu \mathrm{M}$. At this concentration, a stable constriction was maintained for up to 2 hours (Figure S3A). For all subsequent experiments, this $\mathrm{EC}_{50}$ dose of U-46619 was used to precontract the arteries. Following precontraction, addition of iloprost produced a rapid and sustained vasodilation (Figure S3B). The viability and smooth muscle induced relaxation was confirmed by the addition of the nitric oxide donor sodium nitroprusside (Figure S3B). Upon noncumulative applications, iloprost exhibited a nonlinear concentration-dependent relaxation (Figure 4B). Maximal relaxation was observed with $10 \mu \mathrm{M}$ of iloprost, with no further increase at higher concentrations. Therefore, we chose half of this concentration $(5 \mu \mathrm{M})$ for all further experiments. Together, these results confirm the validity of the test system and that iloprost acted as a potent vasodilator on mouse pulmonary arteries.

As the binding of iloprost to different prostanoid receptors produces different vasoactive effects, we next investigated the expression levels of the prostanoid receptors in isolated mouse pulmonary arteries, using real-time PCR. The highest expression was observed for the EP1 together with the TP receptor, followed by the IP receptor. The complete expression levels were as follows EP1 $=\mathrm{TP}>\mathrm{IP} \geq \mathrm{EP} 4=\mathrm{EP} 3>>$ EP2 (Figure 4C).

To compare the pharmacologic efficacy of free and encapsulated iloprost, mouse pulmonary arteries were initially preconstricted with $0.03 \mu \mathrm{M} \mathrm{U}-46619$ and treated with either free or encapsulated iloprost. Free iloprost exhibited 16\% maximal relaxation within 18 minutes, which was maintained for 1 hour. The pure liposomes (without iloprost) produced a slight vasorelaxation after 20 minutes (Figure S4). Liposomal iloprost formulations LI-1 and LI-2 exhibited a nonsignificant increase in vasodilation $(\sim 25 \%)$ as compared with free iloprost (Figure 5A, B, and G). Integration of cholesterol (LI-3 and LI-5) or DOTAP (LI-4 and LI-6) in the liposomal formulations significantly enhanced the maximum vasodilation by up to $\sim 29 \%$ (Figure $5 \mathrm{C}-\mathrm{G}$ ). No significant differences in time to maximal relaxation were observed (Figure $5 \mathrm{H}$ ). The same relaxation curve of free iloprost is depicted in all figures, to enable direct comparison between free iloprost and encapsulated iloprost (Figure 5A-F).

\section{Concentration dependency}

We then selected one formulation that demonstrated an enhanced effect, for further analysis. At $1 \mu \mathrm{M}$, both free and encapsulated iloprost (LI-4) produced similar levels of relaxation (Figure 6A). At $2.5 \mu \mathrm{M}$ and $5 \mu \mathrm{M}$, encapsulated iloprost significantly increased the maximal relaxation when compared with free iloprost (Figure 6B and C). In order to provide direct comparison between the effects of different iloprost and LI-4 doses, the data from Figure 5D is presented again in Figure 6C. Strikingly, liposomal iloprost required half the concentration of iloprost to achieve similar levels of vasodilation as $5 \mu \mathrm{M}$ free iloprost.

\section{Discussion}

The rationale for this study was to create liposomal nanoparticles tailored for the prostacyclin analogue iloprost and to determine their pharmacologic efficacy ex vivo. Previous reports have described very low ( $4 \%$ ) encapsulation efficiencies of
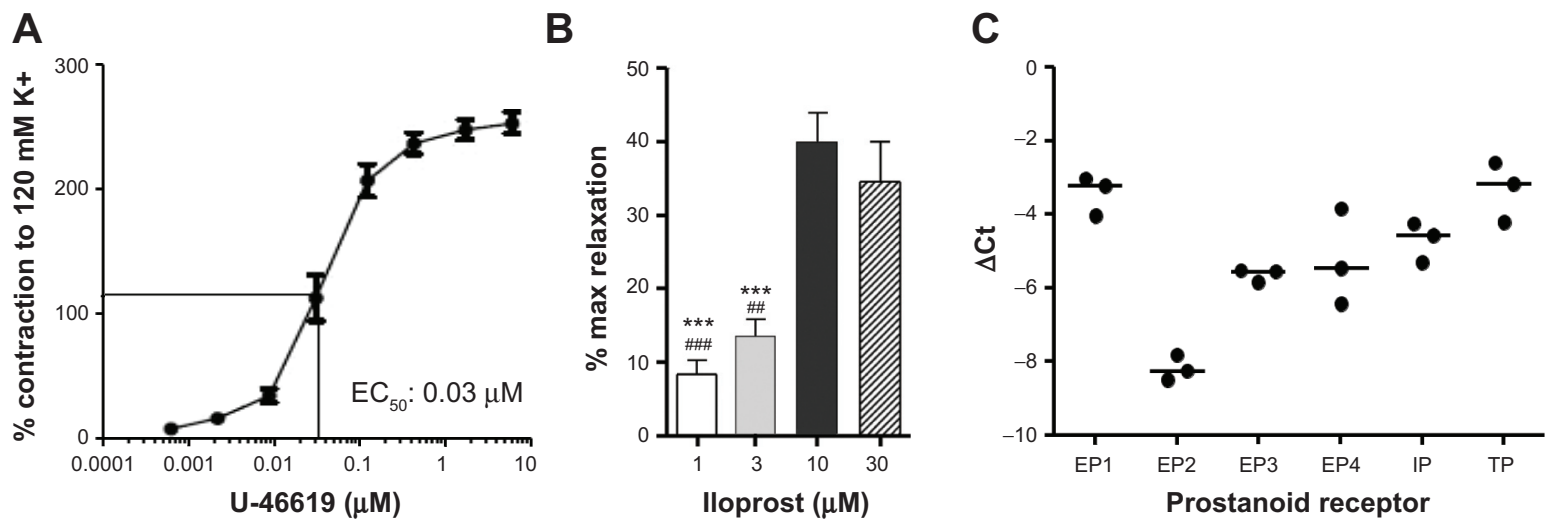

Figure 4 (A) Concentration-dependent contraction of mouse intrapulmonary arteries in response to $U-46619$ compared with $120 \mathrm{mM}$ potassium chloride, $\mathrm{n}=8$. (B) lloprost induced maximum relaxation upon contraction with half-maximal effective concentration $0.03 \mu \mathrm{M}$ of $U-46619$ on mouse intrapulmonary arteries, $\mathrm{n}=5-7$. (C) Real-time PCR analysis of prostanoid receptor expression in isolated mouse pulmonary arteries.

Notes: (B) Data represent mean \pm SEM, $* * * P<0.00$ I compared with $10 \mu \mathrm{M}$ iloprost; $\mathrm{N} P<0.0$ I, ${ }^{\prime \prime} P<0.00$ I compared with $30 \mu \mathrm{M}$ iloprost. One-way ANOVA, followed by Tukey's multiple comparison test, was performed to calculate statistical significance. (C) Lines indicate median.

Abbreviations: ANOVA, analysis of variance; $\mathrm{EC}_{50}$, half-maximal concentration; PCR, polymerase chain reaction; SEM, standard error of the mean. 

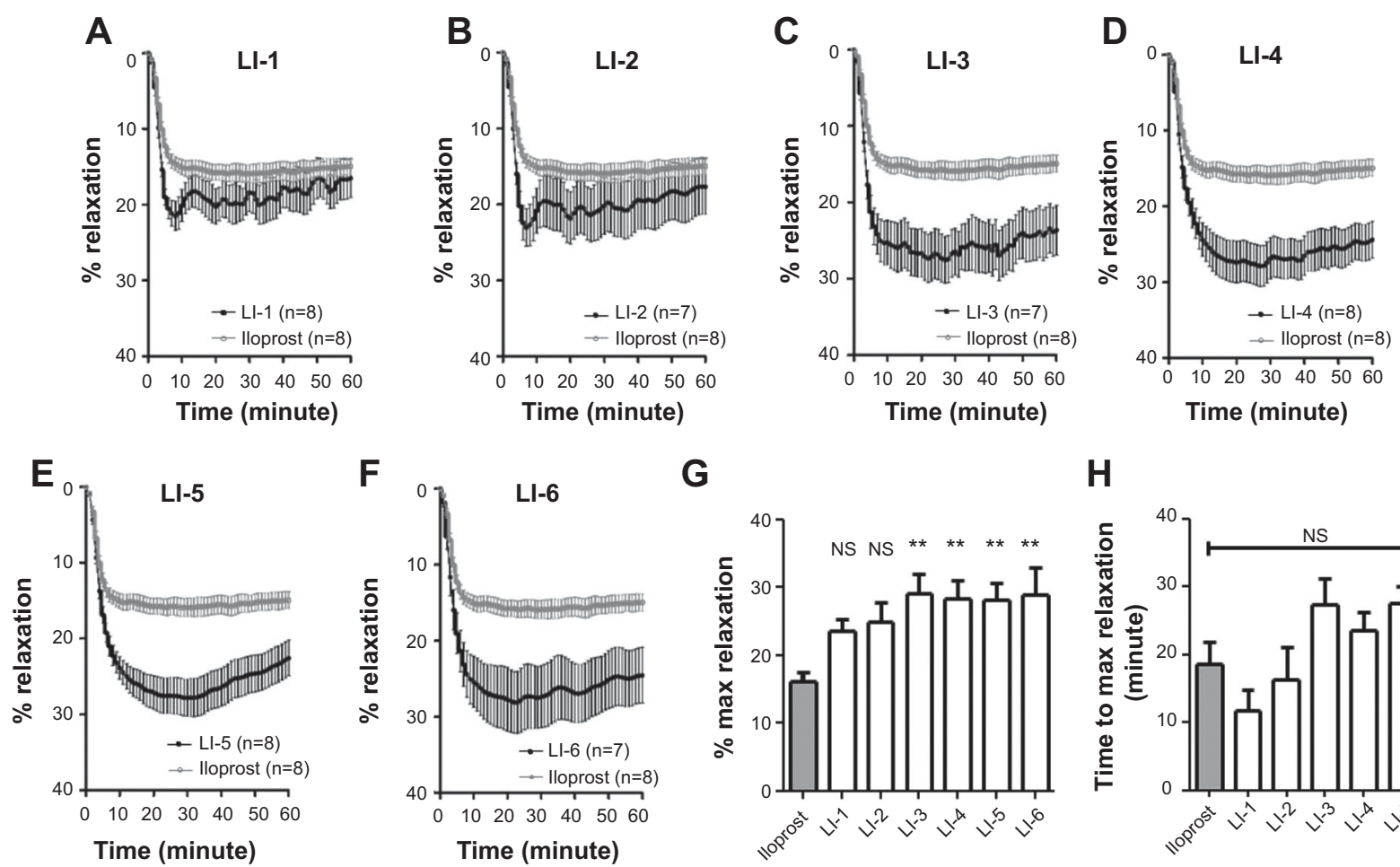

G
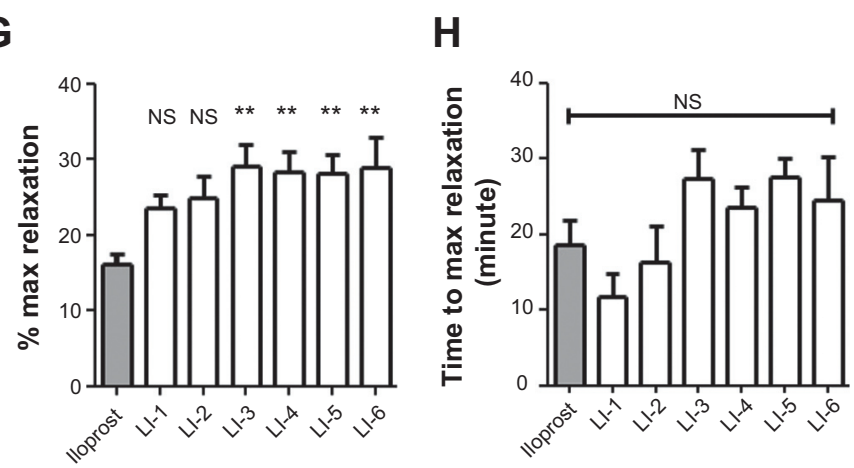

Figure 5 Relaxation kinetics of free and different encapsulated iloprost $(5 \mu \mathrm{M})$ formulations on isolated mouse pulmonary arteries, following $U-46619$ preconstriction. (A) LI-I, (B) LI-2, (C) LI-3, (D) LI-4, (E) LI-5, (F) LI-6 (black symbols) compared with free iloprost (grey symbols). (G) Percentage change from U-466I9 induced contraction. (H) Time to maximum relaxation.

Notes: For easy comparison, the same relaxation curve of free iloprost is depicted in all figures. Data represent mean \pm SEM. $* * P<0.01$. One-way ANOVA with Dunnett's multiple comparison test was used to determine degree of significance between the free and encapsulated iloprost.

Abbreviations: ANOVA, analysis of variance; NS, not significant; SEM, standard error of the mean.
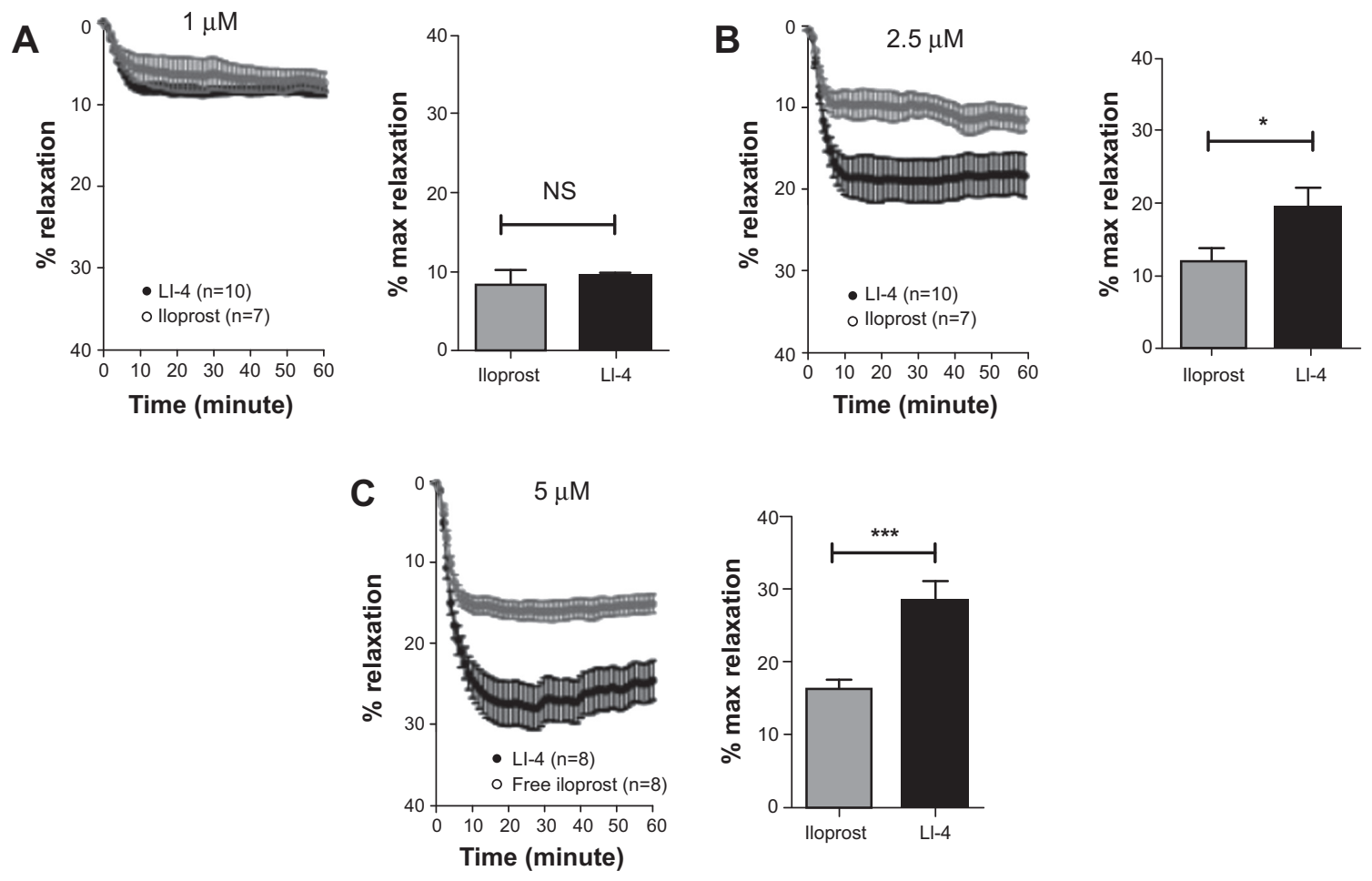

Figure 6 Direct comparison of the relaxation kinetics of LI-4 compared with free iloprost on U-466I9 preconstricted mouse pulmonary arteries. (A) I $\mu$ M iloprost, (B) $2.5 \mu \mathrm{M}$ iloprost, and (C) $5 \mu \mathrm{M}$ iloprost.

Notes: Data represent mean \pm SEM. $* P<0.05$, $* * * P<0.001$. Unpaired $t$-test was used to calculate statistical significance.

Abbreviations: NS, not significant; SEM, standard error of the mean. 
iloprost. ${ }^{23}$ This low encapsulation may be a limiting step for the creation of novel therapeutic strategies. Here we have developed several different liposomal formulations that exhibited very high encapsulation efficiencies (50\%-65\%) (Table 1). Our data indicate that cationic excipients are prerequisite for successful and efficient iloprost encapsulation. Four of six iloprost-liposomal formulations exhibited enhanced relaxation efficacy of preconstricted mouse intrapulmonary arteries.

To date, the use of cationic liposomes has been mostly limited to the encapsulation of negatively charged nucleic acids or oligonucleotides molecules for gene delivery. Recently Bai et al used cationic liposomes to encapsulate low-molecular weight heparin at higher efficiencies ${ }^{27}$ than that reported for neutral liposomes. ${ }^{28}$ We here used SA and the cationic phospholipid DOTAP as the positively charged constituents in our formulations. Differences in the liposome surface charge ( $\zeta$-potential) were dependent on the presence of PVP (LI-2, -5, and -6) or PEG (LI-1, -3, and -4), with PVP-liposomes possessing higher $\zeta$-potential (Table 1). Liposomes containing SA or DOTAP exhibited similar $\zeta$-potential. The higher $\zeta$-potential in the PVP-liposomes presumably originates from the nitrogen-bearing pyrrolidone ring in PVP. The lower $\zeta$-potential of the PEG liposomes (LI-1, -3, and -4) may be due to charge neutralization by the ethoxylate chain present in DPPE-PEG ${ }_{2000}$.

The presence of charged lipids presumably increases the electrostatic interaction between negatively charged iloprost and the liposome, thereby promoting drug encapsulation. Furthermore, the encapsulation efficiency for iloprost was greatly affected by the choice of phospholipid. Saturated phospholipids, like DPPC, form densely packed bilayer structures, which mean very limited void volumes between the acyl chains. In contrast, unsaturated phospholipids, such as POPC, possess higher void volumes and could therefore intercalate more amphiphilic drug within the bilayer, and therefore, could be beneficial for iloprost encapsulation. Cholesterol has been reported to induce a conformational change in the lipid bilayer, imparting cohesive strength to the bilayer and reducing leakiness from liposomes. ${ }^{29}$ Furthermore, cholesterol can increase liposome membrane rigidity and may improve stability in vitro and in vivo. ${ }^{30}$ The incorporation of cholesterol ( $\sim 15$ mole $\%)$ in two of our SA-containing formulations resulted in reduced iloprost encapsulation. This result leads us to speculate that a part of iloprost is preferentially intercalated within the liposome bilayer and to propose that the cholesterol in LI-3 and LI-5 may have acted as a bilayer stiffener, which reduced iloprost capture.
To further promote liposome stability, we modified the surface of liposomes by integrating polymers (PVP) or polymer-conjugated phospholipids (DPPE-PEG ${ }_{2000}$ ). The presence of DPPE-PEG ${ }_{2000}$ has been described to provide an external shield, thereby promoting steric stabilization..$^{29} \mathrm{PVP}$ has been used to coat liposomes and has been reported as an effective steric protector for liposomes in vivo. ${ }^{31-33}$ Incorporation of PVP within a DPPC lipid film promotes interaction with the DPPC acyl chains and consequently, liposome incorporation. ${ }^{34}$ Therefore, we speculate that a similar interaction occurred, with POPC integrating PVP within our liposomes. Thus, the chosen polymers may help to maintain the structural conformation of liposomal nanoparticles and may improve stability.

At both lower and higher iloprost concentrations $(0.2 \mu \mathrm{M}$ and $1 \mu \mathrm{M}$ iloprost), the liposomal formulations exhibited no adverse effects on cell viability (Figure 3 ). This is in line with previous study, which reported that instillation of cationic liposomes loaded with low molecular weight heparin did not significantly elevate lung injury markers. ${ }^{27}$

Due to the difficulty in obtaining human material, we analyzed the pharmacologic efficacy of the liposomal formulations on mouse pulmonary arteries. The thromboxane analogue U-46619 was chosen as the preconstrictor since elevated levels of thromboxane have been reported in $\mathrm{PH}$ patients. ${ }^{35}$ At 10 and $30 \mu \mathrm{M}$ concentration, iloprost produced similar relaxation kinetics, which indicates $\sim 10 \mu \mathrm{M}$ as the maximal effective concentration; therefore, experiments directly comparing free and encapsulated iloprost were performed at $5 \mu \mathrm{M}$. The iloprost-induced relaxation of preconstricted arteries (maximum 40\%) can be attributable to several factors: in mice and humans, iloprost preferentially binds the IP receptor, thereby evoking vasodilation, but also possesses high affinity for the vasoconstrictive EP1 and EP3 receptors. ${ }^{36-38}$ In murine pulmonary arteries, we observed highest expression of the EP1 receptor, followed by IP then EP3 (Figure 4). It is possible that human pulmonary arteries may have different expression levels of these receptors, which may alter the response to iloprost. Our expression data, together with the receptor binding affinity of iloprost, indicates that the strong vasodilative response induced by IP is attenuated by activation of the EP1 and/or EP3 receptors.

One of our major findings was that the pharmacologic efficacy of $5 \mu \mathrm{M}$ free iloprost was equipotent to half the concentration of liposomal encapsulated iloprost $(2.5 \mu \mathrm{M})$ (Figure 6). Studies from Woo et al demonstrated that liposomal encapsulation of deguelin enhanced the antitumor efficacy by reducing the required dose from $4 \mathrm{mg} / \mathrm{kg}$ to $0.4 \mathrm{mg} / \mathrm{kg}$ and 
thus, may prevent potential side effects. ${ }^{39}$ The exact mechanism whereby liposomal iloprost possesses higher activity is currently unclear; however, this may arise from a combination of factors, like shielding the drug from degradation, docking of liposomes to the pulmonary artery, or presentation of iloprost in an orientation that facilitates IP receptor binding. Based on our findings, we propose that liposomal iloprost formulations can enhance the pharmacologic efficacy of iloprost and therefore, may reduce the therapeutic dose.

\section{Conclusion}

Cationic lipids in liposomes promote the encapsulation of the prostacyclin analogue iloprost. Iloprost-loaded cationic liposomes show enhanced vasodilation in comparison with free iloprost. This improved pharmacologic efficacy could be interesting with respect to minimizing the associated manufacturing costs and may be advantageous in terms of systemic side effects.

\section{Acknowledgments}

We thank Gebhard Schratter for excellent technical assistance, and Elisabeth Bock and Elisabeth Pritz for their excellent technical assistance with the electron microscopy. We also thank Akos Heinemann for the scientific review and Harald Köfeler, Astrid Knopf, and Birgit Reiter of the Core Facility for Mass Spectrometry, Centre for Medical Research, Medical University of Graz, for the iloprost quantification.

The study was funded by the Ludwig Boltzmann Institute for Lung Vascular Research, Graz, Austria.

\section{Disclosure}

The authors report no conflicts of interest in this work.

\section{References}

1. Gomberg-Maitland M, Olschewski H. Prostacyclin therapies for the treatment of pulmonary arterial hypertension. Eur Respir J. 2008;31(4): 891-901.

2. Levien TL. Advances in the treatment of Raynaud's phenomenon. Vasc Health Risk Manag. 2010;6:167-177.

3. Piaggesi A, Vallini V, Iacopi E, et al. Iloprost in the management of peripheral arterial disease in patients with diabetes mellitus. Minerva Cardioangiol. 2011;59(1):101-108.

4. Rademaker M, Thomas RH, Provost G, Beacham JA, Cooke ED, Kirby JD. Prolonged increase in digital blood flow following iloprost infusion in patients with systemic sclerosis. Postgrad Med J. 1987;63(742): 617-620.

5. Barst RJ, Rubin LJ, Long WA, et al; Primary Pulmonary Hypertension Study Group. A comparison of continuous intravenous epoprostenol (prostacyclin) with conventional therapy for primary pulmonary hypertension. N Engl J Med. 1996;334(5):296-301.

6. Higenbottam T, Wheeldon D, Wells F, Wallwork J. Long-term treatment of primary pulmonary hypertension with continuous intravenous epoprostenol (prostacyclin). Lancet. 1984;1(8385):1046-1047.
7. Olschewski H, Simonneau G, Galiè N, et al; Aerosolized Iloprost Randomized Study Group. Inhaled iloprost for severe pulmonary hypertension. $N$ Engl J Med. 2002;347(5):322-329.

8. Simonneau G, Barst RJ, Galie N, et al; Treprostinil Study Group. Continuous subcutaneous infusion of treprostinil, a prostacyclin analogue, in patients with pulmonary arterial hypertension: a double-blind, randomized, placebo-controlled trial. Am J Respir Crit Care Med. 2002;165(6): 800-804.

9. Allen TM. Liposomal drug formulations. Rationale for development and what we can expect for the future. Drugs. 1998;56(5):747-756.

10. Waldrep JC. New aerosol drug delivery systems for the treatment of immune-mediated pulmonary diseases. Drugs Today (Barc). 1998;34(6): 549-561.

11. Torchilin VP. Recent advances with liposomes as pharmaceutical carriers. Nat Rev Drug Discov. 2005;4(2):145-160.

12. Woodle MC, Lasic DD. Sterically stabilized liposomes. Biochim Biophys Acta. 1992;1113(2):171-199.

13. Allen TM, Cullis PR. Liposomal drug delivery systems: from concept to clinical applications. Adv Drug Deliv Rev. 2013;65(1):36-48.

14. Bladé J, Sonneveld P, San Miguel JF, et al; DOXIL-MMY-3001 Study Investigators. Efficacy and safety of pegylated liposomal doxorubicin in combination with bortezomib for multiple myeloma: effects of adverse prognostic factors on outcome. Clin Lymphoma Myeloma Leuk. 2011; 11(1):44-49.

15. Sundar S, Jha TK, Thakur CP, Mishra M, Singh VP, Buffels R. Singledose liposomal amphotericin B in the treatment of visceral leishmaniasis in India: a multicenter study. Clin Infect Dis. 2003;37(6):800-804.

16. Muggia FM, Hainsworth JD, Jeffers S, et al. Phase II study of liposomal doxorubicin in refractory ovarian cancer: antitumor activity and toxicity modification by liposomal encapsulation. J Clin Oncol. 1997;15(3): 987-993.

17. Rodriguez MA, Pytlik R, Kozak T, et al; Marqibo Investigators. Vincristine sulfate liposomes injection (Marqibo) in heavily pretreated patients with refractory aggressive non-Hodgkin lymphoma: report of the pivotal phase 2 study. Cancer. 2009;115(15):3475-3482.

18. Sarris AH, Hagemeister F, Romaguera J, et al. Liposomal vincristine in relapsed non-Hodgkin's lymphomas: early results of an ongoing phase II trial. Ann Oncol. 2000;11(1):69-72.

19. Darwis Y, Kellaway IW. Nebulisation of rehydrated freeze-dried beclomethasone dipropionate liposomes. Int J Pharm. 2001;215(1-2): 113-121.

20. Saari M, Vidgren MT, Koskinen MO, Turjanmaa VM, Nieminen MM. Pulmonary distribution and clearance of two beclomethasone liposome formulations in healthy volunteers. Int J Pharm. 1999;181(1):1-9.

21. Gupta V, Gupta N, Shaik IH, et al. Liposomal fasudil, a rho-kinase inhibitor, for prolonged pulmonary preferential vasodilation in pulmonary arterial hypertension. J Control Release. 2013;167(2):189-199.

22. Stark B, Debbage P, Andreae F, Mosgoeller W, Prassl R. Association of vasoactive intestinal peptide with polymer-grafted liposomes: structural aspects for pulmonary delivery. Biochim Biophys Acta. 2007;1768(3): 705-714.

23. Kleemann E, Schmehl T, Gessler T, Bakowsky U, Kissel T, Seeger W. Iloprost-containing liposomes for aerosol application in pulmonary arterial hypertension: formulation aspects and stability. Pharm Res. 2007;24(2):277-287.

24. Bangham AD, Standish MM, Watkins JC. Diffusion of univalent ions across the lamellae of swollen phospholipids. J Mol Biol. 1965;13(1): $238-252$.

25. Folch J, Lees M, Sloane Stanley GH. A simple method for the isolation and purification of total lipides from animal tissues. $J$ Biol Chem. 1957;226(1):497-509.

26. Kwapiszewska G, Chwalek K, Marsh LM, et al. BDNF/TrkB signaling augments smooth muscle cell proliferation in pulmonary hypertension. Am J Pathol. 2012;181(6):2018-2029.

27. Bai S, Gupta V, Ahsan F. Cationic liposomes as carriers for aerosolized formulations of an anionic drug: safety and efficacy study. Eur J Pharm Sci. 2009;38(2):165-171. 
28. Song YK, Kim CK. Topical delivery of low-molecular-weight heparin with surface-charged flexible liposomes. Biomaterials. 2006;27(2): 271-280.

29. Bedu-Addo FK, Tang P, Xu Y, Huang L. Effects of polyethyleneglycol chain length and phospholipid acyl chain composition on the interaction of polyethyleneglycol-phospholipid conjugates with phospholipid: implications in liposomal drug delivery. Pharm Res. 1996;13(5): 710-717.

30. Kirby C, Clarke J, Gregoriadis G. Effect of the cholesterol content of small unilamellar liposomes on their stability in vivo and in vitro. Biochem J. 1980;186(2):591-598.

31. Torchilin VP, Shtilman MI, Trubetskoy VS, Whiteman K, Milstein AM. Amphiphilic vinyl polymers effectively prolong liposome circulation time in vivo. Biochim Biophys Acta. 1994;1195(1):181-184.

32. Torchilin VP, Trubetskoy VS, Whiteman KR, Caliceti P, Ferruti P, Veronese FM. New synthetic amphiphilic polymers for steric protection of liposomes in vivo. J Pharm Sci. 1995;84(9):1049-1053.

33. Torchilin VP, Levchenko TS, Whiteman KR, et al. Amphiphilic poly-N-vinylpyrrolidones: synthesis, properties and liposome surface modification. Biomaterials. 2001;22(22):3035-3044.

34. Savva M, Torchilin VP, Huang L. Effect of Polyvinyl Pyrrolidone on the Thermal Phase Transition of 1,2 Dipalmitoyl-sn-glycero3-phosphocholine Bilayer. J Colloid Interface Sci. 1999;217(1): $160-165$.
35. Christman BW, McPherson CD, Newman JH, et al. An imbalance between the excretion of thromboxane and prostacyclin metabolites in pulmonary hypertension. N Engl J Med. 1992;327(2):70-75.

36. Abramovitz M, Adam M, Boie Y, et al. The utilization of recombinant prostanoid receptors to determine the affinities and selectivities of prostaglandins and related analogs. Biochim Biophys Acta. 2000;1483(2): 285-293.

37. Kiriyama M, Ushikubi F, Kobayashi T, Hirata M, Sugimoto Y, Narumiya S. Ligand binding specificities of the eight types and subtypes of the mouse prostanoid receptors expressed in Chinese hamster ovary cells. Br J Pharmacol. 1997;122(2):217-224.

38. Whittle BJ, Silverstein AM, Mottola DM, Clapp LH. Binding and activity of the prostacyclin receptor (IP) agonists, treprostinil and iloprost, at human prostanoid receptors: treprostinil is a potent DP1 and EP2 agonist. Biochem Pharmacol. 2012;84(1):68-75.

39. Woo JK, Choi DS, Tran HT, Gilbert BE, Hong WK, Lee HY. Liposomal encapsulation of deguelin: evidence for enhanced antitumor activity in tobacco carcinogen-induced and oncogenic K-ras-induced lung tumorigenesis. Cancer Prev Res (Phila). 2009;2(4):361-369. 


\section{Supplementary materials}
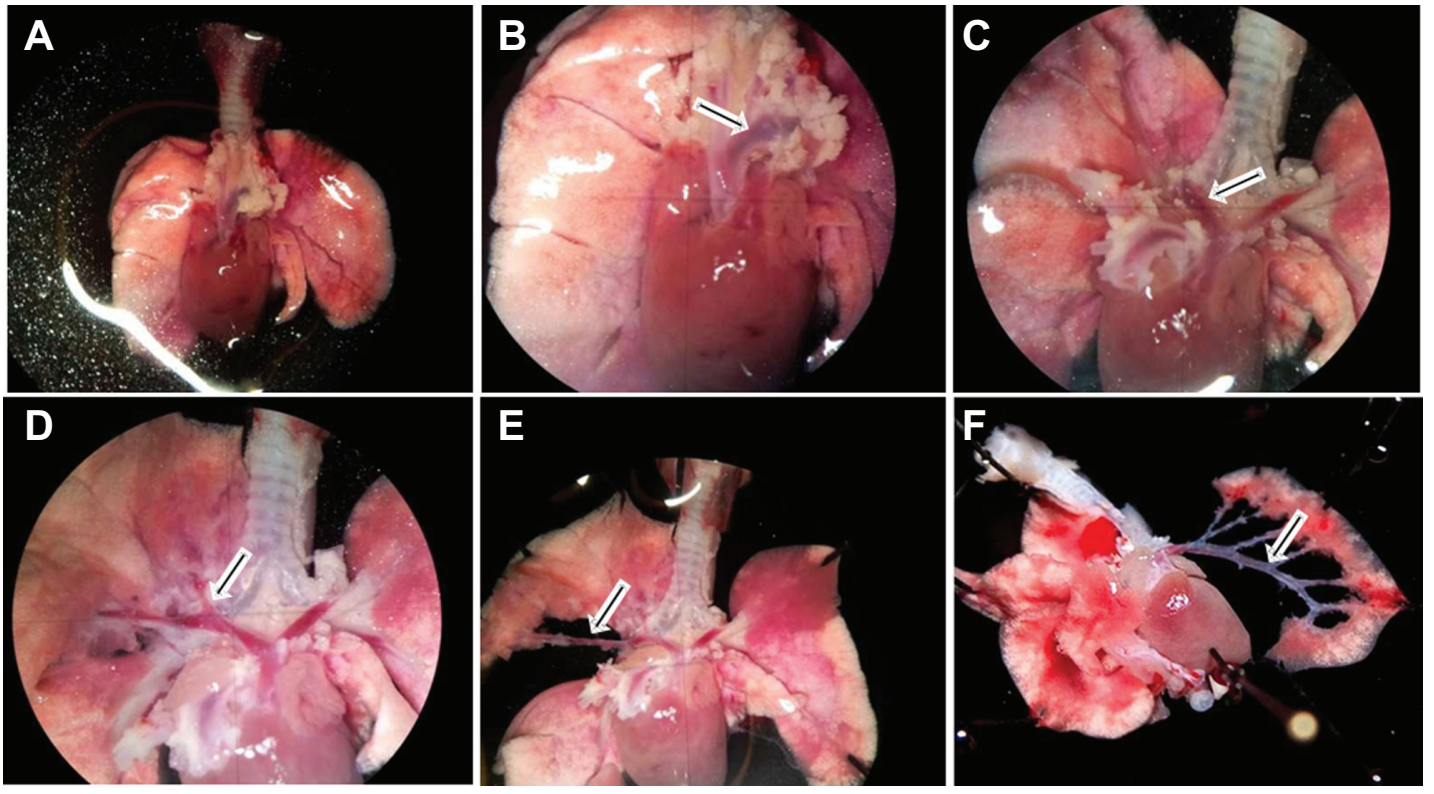

Figure SI Steps involved in the preparation of mouse intrapulmonary arteries.

Notes: (A) Heart and lungs were removed en bloc. (B) Removal of the adipose tissue surrounding aorta (arrow). (C) Cutting the aorta exposed the pulmonary artery (arrow). (D) Removal of lung parenchyma exposed further bifurcations (arrow). (E) Further removal of the lung parenchyma freed the pulmonary artery (arrow). (F) Fully exposed pulmonary arteries (arrow).

\section{A LI-1}

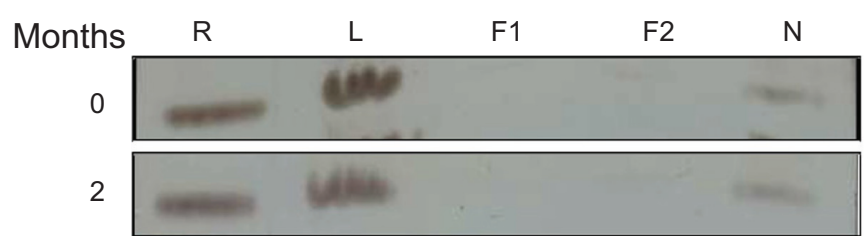

B

\section{LI-2}

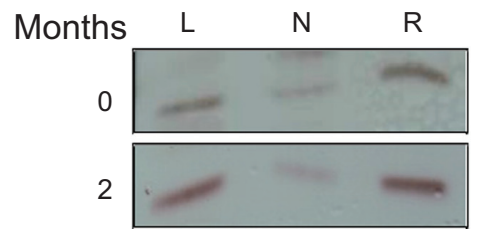

Figure S2 Effects of storage on iloprost encapsulation. Liposomes were stored for 2 months at $4^{\circ} \mathrm{C}$ and encapsulation was then analyzed by thin layer chromatography. (A) $\mathrm{LI}-\mathrm{I}$ and (B) $\mathrm{LI}-2$

Notes: Band for $2 \mu \mathrm{g}$ iloprost applied as reference (R), bands for liposomal encapsulated iloprost (L), fractions of the obtained flow through (filtrates) containing no iloprost from Amicon ${ }^{\circledast}$ filter unit (Merck KGaA, Darmstadt, Germany) (FI, F2), bands of nonencapsulated iloprost (N) eluted from the filter unit via an ethanol wash.
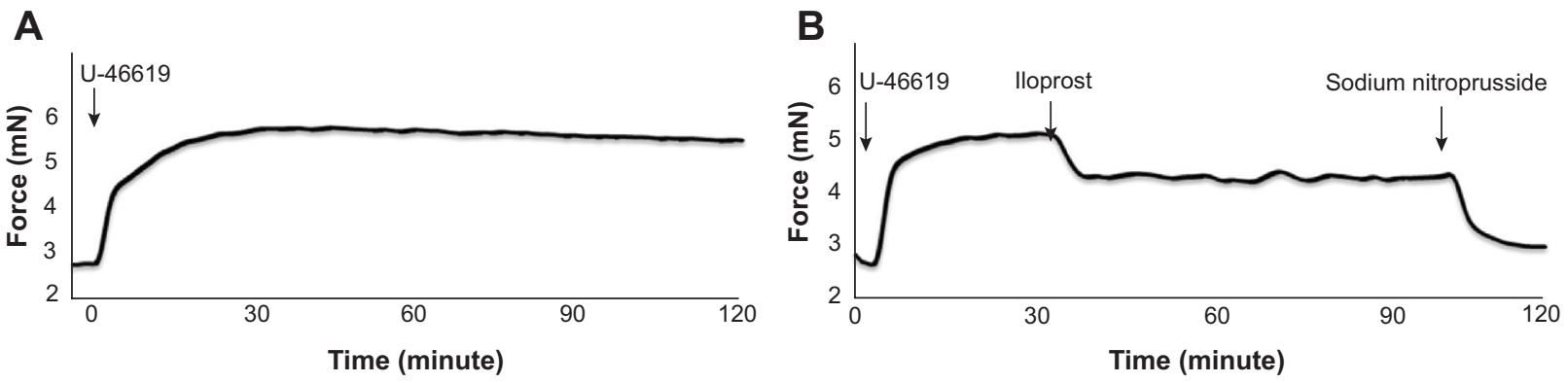

Figure S3 Representative real-time curve, from isometric tension measurements using a wire myograph.

Notes: (A) Duration of vasoconstriction following $0.03 \mu \mathrm{MU}$-46619-induced vasoconstriction. (B) Vasorelaxation induced by addition of free iloprost (5 $\mu \mathrm{M}$ ) and the nitric oxide donor, sodium nitroprusside $(10 \mu \mathrm{M})$, on U-46619-induced preconstricted mouse pulmonary arteries. 
A

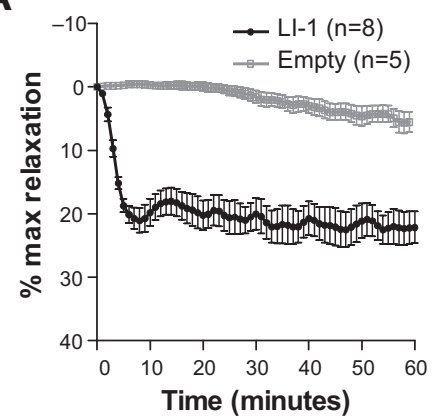

C

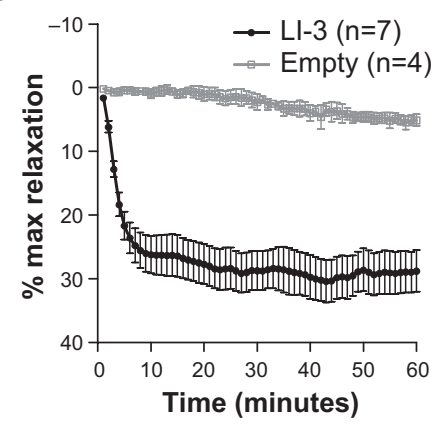

E

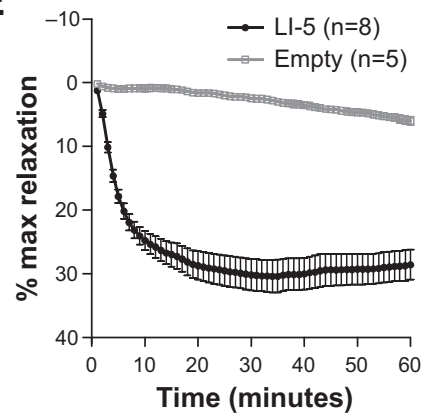

B

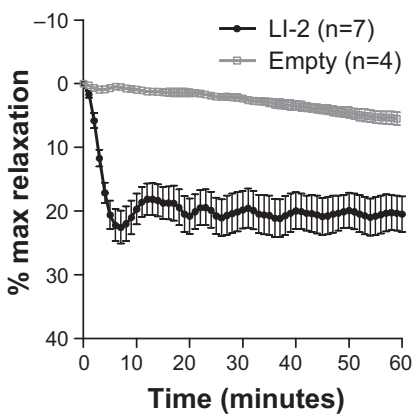

D

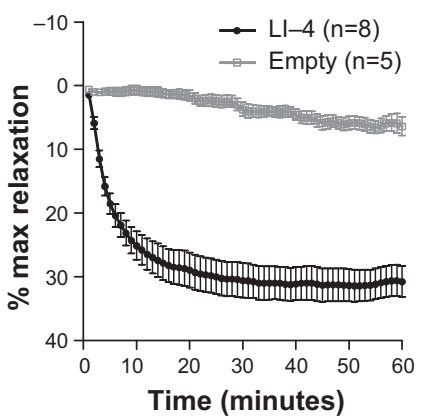

$\mathbf{F}$

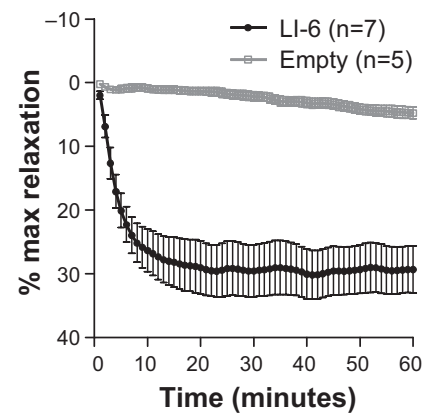

Figure S4 Relaxation kinetics of liposomes (empty) and encapsulated iloprost (5 $\mu \mathrm{M}$ iloprost) on isolated mouse pulmonary arteries, following $U-46619$ preconstriction. (A) LI-I, (B) LI-2, (C) LI-3, (D) LI-4, (E) LI-5, and (F) LI-6.

Notes: Relaxation values obtained by empty liposomes were subtracted from the respective liposomal iloprost formulation to determine the relative relaxation for each formulation. Data represent mean \pm SEM.

Abbreviation: SEM, standard error of the mean.

International Journal of Nanomedicine

\section{Publish your work in this journal}

The International Journal of Nanomedicine is an international, peerreviewed journal focusing on the application of nanotechnology in diagnostics, therapeutics, and drug delivery systems throughou the biomedical field. This journal is indexed on PubMed Central, MedLine, CAS, SciSearch ${ }^{\circledR}$, Current Contents ${ }^{\circledR} /$ Clinical Medicine,

\section{Dovepress}

Journal Citation Reports/Science Edition, EMBase, Scopus and the Elsevier Bibliographic databases. The manuscript management system is completely online and includes a very quick and fair peer-review system, which is all easy to use. Visit http://www.dovepress.com/ testimonials.php to read real quotes from published authors. 